\title{
Performance Evaluation of Zigbee Protocol for Habitat Monitoring
}

\author{
Swati V. Sankpal \\ D. Y. Patil College of Eng., \\ Kolhapur \\ Shivaji University Kolhapur
}

\author{
Dr. Vishram Bapat, \\ Shivaji University, \\ Kolhapur
}

\begin{abstract}
Habitat and environmental monitoring are driving applications for wireless sensor network. This work present a performance evaluation of Zigbee which is IEEE 802.15.4 standard, focusing on energy required for sending and receiving uplink packets and hence battery lifetime. We analyzed the performance based on these two metrics. The analytical and simulation results are perfectly matched
\end{abstract}

\section{General Terms}

Wireless sensor networks

\section{Keywords}

WSN,ZigBee,Habitat Monitoring

\section{INTRODUCTION}

Wireless adhoc network is a generic term grouping different networks, which are self organizing, meaning that there is neither a centralized administration nor a fixed network infrastructure, and communication links are wireless. A wireless sensor network is an adhoc network consisting of spatially distributed autonomous sensor nodes which are equipped with radio transceiver, a microcontroller, an energy source (usually a battery) and sensor to cooperatively monitor or environmental conditions.

In wireless sensor networks, maximizing battery lifetime is very important design criterion, because in many applications charging or recharging battery after deployment is normally not economical or not feasible.

Current trend in computer communication is gearing towards embedded ubiquitous computing. Advances in wireless communications and microelectronics enabled the development of low cost sensors which are constantly being adapted for pervasive communication paradigm. One of the main objectives of the MAC protocol for WSN is to minimize power consumption while providing reliable, low data rate transmission.

Unlike other wireless network, it is generally very hard to charge/replace the battery, which gives the way to the primary objective of maximizing network lifetime, leaving the other performance metrics as secondary objective. Since the communication of sensor nodes will be more energy consuming than their computations, it is primary concern that communications is minimized whole achieving the desired network operation.

Habitat and environmental monitoring represent a class of sensor network applications with enormous potential benefits for scientific communities and society as whole. Such applications share a common structure, where field of sensors are tasked to take periodic reading and report the result and derived values to a central repository. In the context of habitat monitoring, wireless sensor networks offers significant advantages. Individual devices can be made significantly numerous to take measurements at many locations of interest and mitigate errors arising from the interpolation and extrapolation from coarser-grained samples. They can be sufficiently small to be co-located with. phenomena of interest without altering the parameters to be measured. And they can be unobtrusively embedded in the environment without creating conspicuous landmarks that change the behaviors of its inhabitants.

This paper presents a comparison of analytical and simulation model of Zigbee, which is low power MAC. This paper describes comparison results of energy consumption required for sending and receiving packets as well as lifetime of battery

\section{RELATED WORK}

The smooth operation of any wireless network depends, to a large extent, on the effectiveness of the low-level Medium Access Control (MAC) layer responsible for sharing the ether. A MAC protocol determines the next node to access the medium, tries to ensure that no two nodes are interfering with each other's transmissions, and deals with the situation when they do. TDMA-based protocols, in contrast to contention-based protocols, are very effective at avoiding collisions and have a built-in duty cycle mitigating idle listening. They require, however, some authority (e.g., a dedicated access point) to orchestrate activities within a cell. This complicates their deployment in multi-hop ad-hoc (sensor) networks where nodes are equal and have limited resources.

The second approach mitigating idle listening is the S-MAC protocol, a true MAC protocol, which also addresses the overheads caused by collisions, overhearing, and protocol overhead. The basic idea of this contention-based protocol is that time is divided into relatively large frames. Every frame has two parts: an active part and a sleeping part. During the sleeping part, a node turns off its radio to preserve energy.

During the active part, it can communicate with its neighbors and send any messages queued during the sleeping part on idle listening, is reduced. The exact savings are under control of the application. Consequently, it results in increase in latency, and reduction in throughput. S-MAC needs some synchronization between nodes, but that is not as critical as in TDMA-based protocols. The S-MAC protocol uses the RTS/CTS/DATA/ACK signaling scheme from 802.11 to reduce the number of collisions caused by the hidden-node problem. S-MAC includes message passing support to reduce protocol overhead when streaming a sequence of message fragments. 
An energy-saving protocol for sensor networks considered here is the T-MAC protocol, which automatically adapts the duty cycle to the network traffic. As with S-MAC, nodes form a virtual cluster to synchronize themselves on the beginning of a frame. But instead of using a fixed-length active period, T-MAC uses a time-out mechanism to dynamically determine the end of the active period. If receiver does not receive any message during time out interval, it goes to sleep and if it receives such message, the time start starts afresh after reception of message. The basic T-MAC scheme suffers from so called early sleep problem which can reduce throughput.

B-MAC, developed at the University of California at Berkeley, is a CSMA-based technique that utilizes low power listening and an extended preamble to achieve low power communication. Nodes have an awake and a sleep period, and each node can have an independent schedule. If a node wishes to transmit, it precedes the data packet with a preamble that is slightly longer than the sleep period of the receiver. During the 'awake' period, a node samples the medium and if a preamble is detected it remains awake to receive the data. With the extended preamble, a sender is assured that at some point during the preamble the receiver will wake up, detect the preamble, and remain awake in order to receive the data. B-MAC also provides an interface by which the application can adjust the sleep schedule to adapt to changing traffic loads. The method of adaptation is left to the application developer. It is shown that BMAC surpasses existing protocols in terms of throughput, latency, and for most cases energy consumption. While B-MAC performs quite well, it suffers from the overhearing problem, and the long preamble dominates the energy usage.

WiseMAC, which is based on ALOHA, also uses preamble sampling to achieve low power communications in infrastructure sensor networks. WiseMAC uses a similar technique to B-MAC, but the sender learns the schedules of the receiver awake periods, and schedules its transmission so as to reduce the length of the extended preamble. . In addition, for low traffic loads where the preamble is longer than the data frame, WiseMAC repeats the data frame in place of the extended preamble.

Receivers process this data frame and if the node is not the intended recipient it returns to sleep. If the node is the recipient, it remains awake until the end of the transmission and sends an acknowledgement. While WiseMAC solves many of the problems associated with low power communications, it does not provide a mechanism by which nodes can adapt to changing traffic patterns.

\section{IDENTIFICATION OF PROBLEM AND ORGANIZATION}

As WSN are useful in many monitoring applications, in this paper we concentrating one of the applications of WSN, which is Habitat monitoring. For Habitat monitoring following as the core set of requirements.

1 Energy efficiency: The sensor nodes should not need refreshing of batteries for at least 6 months.

2. Remote querying and reconfigurability: It should be possible to query the data in several formats and to reconfigure the monitoring parameters via the Internet.
3 Ease of deployment: The client should be able deploy the system without any need for special configuration.

4 Reliability: The provided data should be real-time and highfidelity. The system should be available $99 \%$ of the time and should recover from a crash quickly.

As very prior important parameter for Habitat monitoring is energy efficiency, from the above survey of energy efficient MAC , we have decided to implement ZigBee MAC protocols for Habitat Monitoring application and compare results with respect to energy saving and battery lifetime.

The organization of our work is like this: Part 4.1) in section 4 represents analytical model for Zigbee part 4.2) of section 4 represents simulation model for Zigbee computation details.

The definition and default values of parameters used for computation are listed in table (I). For simplicity computation is carried out for star topology and for uplink transmission. Poisson process traffic model is used. In this probability density function is given as, $P(t)=\lambda e^{-\lambda t}$

and cumulative distribution function is,

$f(t)=1-e^{-\lambda t}$

\section{ZIGBEE COMUTATION}

\subsection{Zigbee analytical computation details}

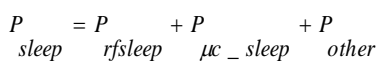

$\mathrm{E}_{\text {no_traffic }}=P_{m} \times\left(T_{s_{-} r f}+\frac{T_{b c n}}{T_{\text {cycle }}}\right)+P_{\text {sleep }} \times T_{\text {sleep }}$

$\mathrm{E}=P_{\text {slave }} \times\left(C A P+\mathrm{T}_{\mathrm{t}}+\mathrm{T}_{\text {data }}+T_{\text {ack }}\right)$

$=$ Expected energy to send a packet from slave to master.

$\mathrm{E}=\underset{m}{P} \times\left(T_{b c n_{-} \text {extra }}+\mathrm{T}_{\mathrm{t}}+\mathrm{T}_{\text {data }}+T_{\text {ack }}\right)+P_{\text {sleep }} \times T_{\text {sleep }}$

$=$ Expected energy to receive packet from slave.

$E_{\text {oh }}=P_{\text {slave }} \times T_{\text {bcn_extra }}$

$=$ Energy consumption for overhearer.

$E_{s_{-} \text {avg }}=\frac{E_{S}}{N}+E_{o h} \times\left(\frac{N-1}{N}\right)$

$=$ Average sending energy.

$E_{r_{-} a v g}=E_{r}+E_{o h} \times\left(\frac{N-1}{N}\right)$

$=$ Average receiving energy 


$$
\begin{aligned}
& E_{\lambda_{-} E_{s}}=E_{s_{-} a v g} \times \lambda \times N+E_{n o_{-} \text {traffic }} \\
& E_{\lambda_{-} E_{s_{\text {days }}}=\frac{108}{864} \times E_{\lambda_{-} E_{s}}} E_{\lambda_{-} E_{r}}=E_{r_{-} a v g} \times \lambda+E_{n o_{-} \text {traffic }} \\
& E_{\lambda_{-} E_{r_{\text {days }}}=\frac{108}{864} \times E_{\lambda_{-}} E_{r}}
\end{aligned}
$$

\subsection{Simulation details}

The definition and default values of parameters used for computation are listed in table (I).

For simplicity computation is carried out for star topology and for uplink transmission. Poisson process traffic model is used. In this probability density function is given as,

$$
\begin{aligned}
& P(t)=\lambda e^{-\lambda t} \text { and cumulative distribution function is, } \\
& f(t)=1-e^{-\lambda t}
\end{aligned}
$$

\begin{tabular}{|c|c|c|}
\hline Parameter & Description & Value \\
\hline$U_{\text {system }}$ & Supply voltage of the System & $3 \mathrm{~V}$ \\
\hline$B_{\text {capacity }}$ & Capacity of the battery & $\begin{array}{l}1000 \\
\mathrm{mAh}\end{array}$ \\
\hline$f_{\mu C}$ & $\begin{array}{l}\text { Working frequency of the } \\
\text { microcontroller }\end{array}$ & $9 \mathrm{MHz}$ \\
\hline$P_{r f \text { sleep }}$ & $\begin{array}{l}\text { Power consumption of the RF } \\
\text { in sleep mode }\end{array}$ & $27 \mu \mathrm{W}$ \\
\hline$P_{\mu c \text { sleep }}$ & $\begin{array}{l}\text { Power consumption of the } \\
\text { microcontroller in sleep mode }\end{array}$ & $90 \mu \mathrm{W}$ \\
\hline$P P_{\text {others }}$ & $\begin{array}{l}\text { Power consumption of other } \\
\text { components: memory, RTC, } \\
\text { etc. }\end{array}$ & $27 \mu \mathrm{W}$ \\
\hline$\overline{P_{m}}$ & $\begin{array}{l}\text { Power consumption of the RF } \\
\text { in } \mathrm{RX} \text { mode }\end{array}$ & $27 \mathrm{~mW}$ \\
\hline$P_{\text {slave }}$ & $\begin{array}{l}\text { Power consumption of the RF } \\
\text { in TX mode }\end{array}$ & $\begin{array}{l}39.9 \\
\mathrm{~mW}\end{array}$ \\
\hline$P_{\mu c}$ & $\begin{array}{l}\text { Power consumption of the } \\
\text { microcontroller in working } \\
\text { mode }\end{array}$ & $\begin{array}{l}32.7 \\
\mathrm{~mW}\end{array}$ \\
\hline$T_{\text {to } r x}$ & Setup time of the RF RX mode & $2.2 \mathrm{~ms}$ \\
\hline$T_{\text {to } t x}$ & Setup time of the RF TX mode & $1.1 \mathrm{~ms}$ \\
\hline$T_{t}$ & $\begin{array}{l}\text { Transition time of the RF } \\
\text { between RX and TX mode }\end{array}$ & $\mathrm{T}_{\text {to rx }}$ \\
\hline$T_{s r s s i}$ & Setup time of the RF RSSI & $0.4 \mathrm{~ms}$ \\
\hline$T_{s_{-} r f}$ & $\begin{array}{l}\text { Setup time of the RF from } \\
\text { sleep to awake }\end{array}$ & $\mathrm{T}_{\text {to rx }}$ \\
\hline$T_{s \mu c}$ & $\begin{array}{l}\text { Setup time of the } \\
\text { microcontroller from sleep to } \\
\text { awake }\end{array}$ & $2.6 \mathrm{~ms}$ \\
\hline$T_{\text {samplerssi }}$ & $\begin{array}{l}\text { Time for sampling the channel } \\
\text { if only RSSI is used }\end{array}$ & $0.4 \mathrm{~ms}$ \\
\hline$R_{\text {data }}$ & $\begin{array}{l}\text { Transmission rate for DATA } \\
\text { frame }\end{array}$ & $\begin{array}{r}100 \\
\mathrm{bit} / \mathrm{s}\end{array}$ \\
\hline$R_{\text {wus }}$ & $\begin{array}{l}\text { Transmission rate for wake- } \\
\text { up-signal }\end{array}$ & $70 \mathrm{bit} / \mathrm{s}$ \\
\hline
\end{tabular}

Free-space propagation model is used to detect signal strength. CSMA technique is used to access the medium. Backoff counter is set to maximum value and when it hits to zero medium is accessed

Table I: Parameters of the WSN.

\begin{tabular}{|c|l|c|}
\hline$L_{\text {ack }}$ & Length of ACK frame & $96 \mathrm{bit}$ \\
\hline$L_{\text {swuf }}$ & $\begin{array}{l}\text { Length of a short wake-up- } \\
\text { frame }\end{array}$ & $326 \mathrm{bit}$ \\
\hline$L_{\text {ip } \max }$ & Maximum length of IP packet & $\begin{array}{c}576 \times 8 \\
\text { bit }\end{array}$ \\
\hline$L_{\text {data max }}$ & $\begin{array}{l}\text { Maximum length of DATA } \\
\text { frame }\end{array}$ & $7200 \mathrm{bit}$ \\
\hline$L_{\text {bcn }}$ & $\begin{array}{l}\text { Length of an IEEE 802.15.4 } \\
\text { MAC beacon frame }\end{array}$ & $276 \mathrm{bit}$ \\
\hline$L_{\text {bcn extra }}$ & $\begin{array}{l}\text { Length of an IEEE 802.15.4 } \\
\text { frame indication in beacon }\end{array}$ & $96 \mathrm{bit}$ \\
\hline$L_{\text {cmd }}$ & $\begin{array}{l}\text { Length of an IEEE 802.15.4 } \\
\text { MAC data request command } \\
\text { frame }\end{array}$ & $228 \mathrm{bit}$ \\
\hline$L_{\text {to addr }}$ & $\begin{array}{l}\text { Length of a frame until the } \\
\text { destination address }\end{array}$ & $192 \mathrm{bit}$ \\
\hline$T_{\text {ack }}$ & $\begin{array}{l}\text { Time to transmit an ACK } \\
\text { frame }\end{array}$ & $0.96 \mathrm{~ms}$ \\
\hline$T_{\text {swuf }}$ & $\begin{array}{l}\text { Time to transmit an SWUF } \\
\text { frame }\end{array}$ & $4.66 \mathrm{~ms}$ \\
\hline$T_{\text {data }}$ & $\begin{array}{l}\text { Time to transmit a DATA } \\
\text { frame }\end{array}$ & - \\
\hline$T_{\text {data max }}$ & $\begin{array}{l}\text { Time to transmit a DATA } \\
\text { frame with maximal length }\end{array}$ & $72 \mathrm{~ms}$ \\
\hline$T_{b c n}$ & $\begin{array}{l}\text { Time to transmit an IEEE } \\
802.15 .4 \text { beacon frame }\end{array}$ & $2.76 \mathrm{~ms}$ \\
\hline$T_{\text {bcn extra }}$ & $\begin{array}{l}\text { Time to transmit an IEEE } \\
802.15 .4 \text { frame indication in } \\
\text { beacon }\end{array}$ & $0.96 \mathrm{~ms}$ \\
\hline
\end{tabular}




\section{FLOWCHART}

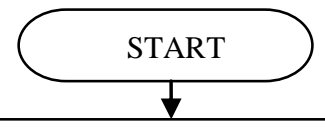

Initialize power consumption, setup time, power consumption, set up time, power consumption in sleep mode, power transmitted by slave, time to transmit data frame, time to transmit acknowledgement, time to transmit beacon frame

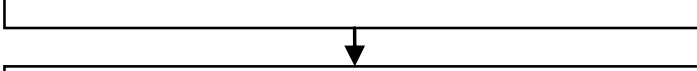

Set contention access period randomly

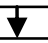

Calculate $\mathrm{T}$ cycle, Power Consumption in no traffic case, expected energy to send a packet, expected energy to receive a packet, power consumption of an overhearer.

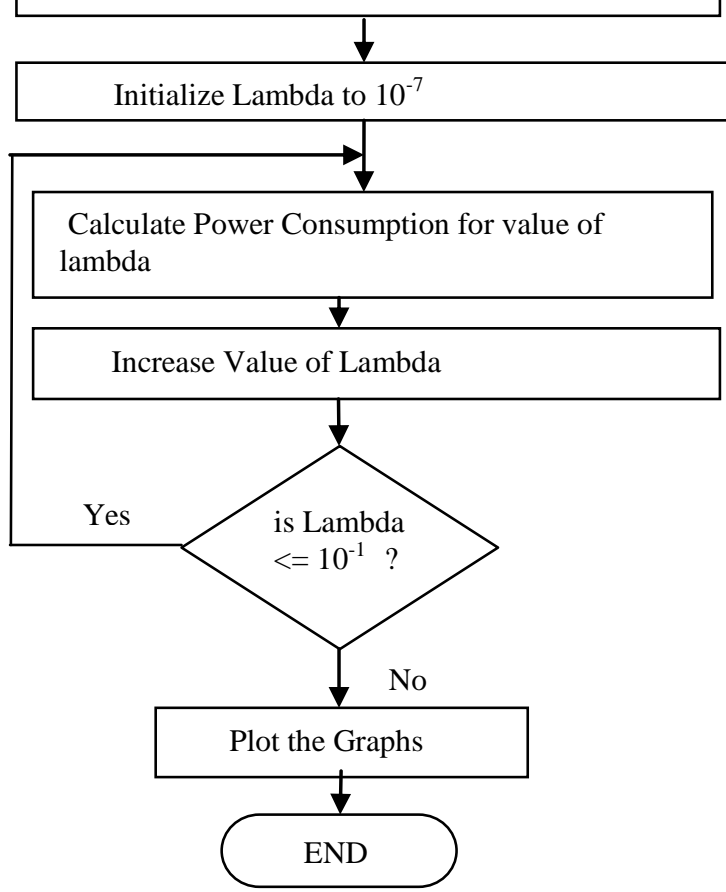

\section{RESULTS}

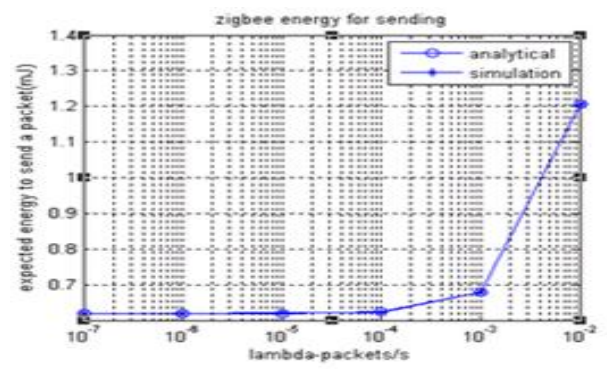

Fig.1-Energy required for sending packets/sec

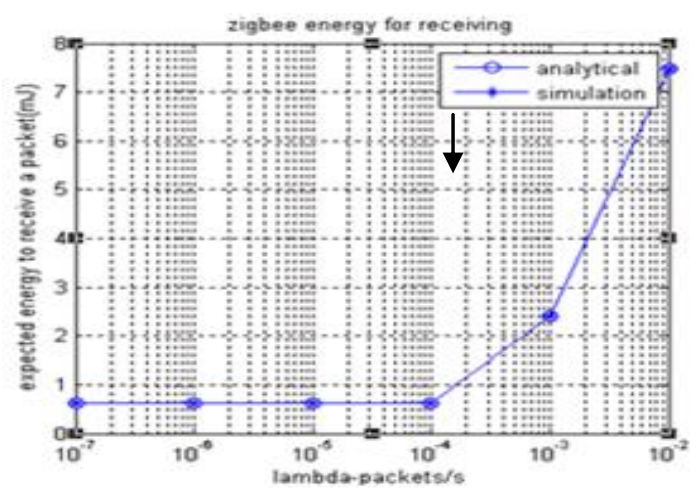

Fig.2-Energy required for receiving packets/sec

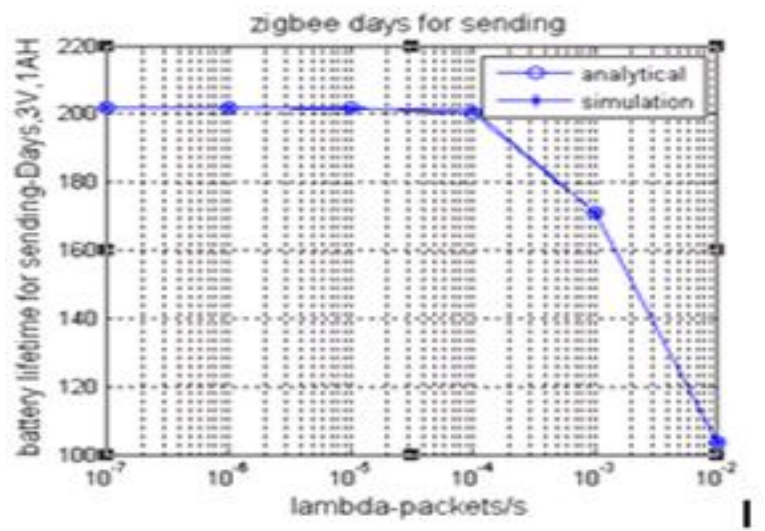

Fig.3 Battery life-time required for sending packets/sec

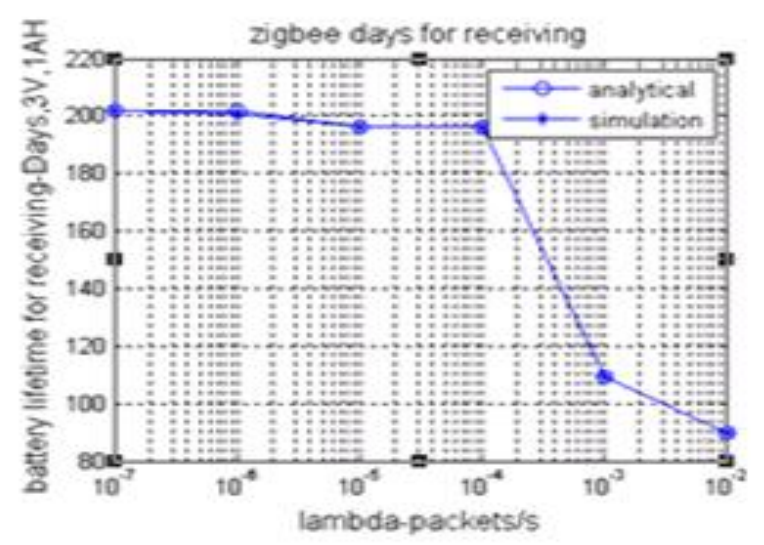

Fig.4 Battery life-time required for receiving packets/sec

\section{CONCLUSION}

We have presented comparison of analytical and simulation results of Zigbee. From the results it is seen that ZigBee MAC is suitable for low traffic. The results indicate that the analytical and simulation model agree. Hence the simulation model is validated. The work on this is in progress, it will be interesting to modify this simulation model to improve the energy efficiency of the WSN. 


\section{REFERENCES}

[1] Jan M. Rabaey, M. Josie Ammer, Julio L. da Silva, Danny Patel, and Shad Roundry. "PicoRadio Supports Ad Hoc Ultra-Low Power Wireless Networking." IEEE Computer, 33(7):42-48, July 2000.

[2] Christian C. Enz, Amre El-Hoiydi, Jean-Dominique Decotignie, and Vincent Peiris. "WiseNET: An UltralowPower Wireless Sensor Network Solution." IEEE Computer, 37(8):62-70, August 2004.

[3] V. Raghunathan, C. Schurgers, S. Park, and M. B. Srivastava. "Energy-AwareWireless Microsensor Networks.” IEEE Signal Processing Magazine, 19:40-50, March 2002.

[4] C. E. Jones, K. M. Sivalingam, P. Agrawal, and J. C. Chen. "A Survey Of Energy Efficient Network Protocols for Wireless Networks." IEEE Wireless Networks, 7(4):343358, July 2001.

[5] J. P. Monks, V. Bharghavan, and W. E. Hwu. "A Power Controlled Multiple Access Protocol for Wireless Packet Networks." In INFOCOM, pages 219-288, April 2001.

[6] W. R. Heinzelman and A. Sinha and A. Wang and A. P. Chandrakasan. "Energy-Scalable Algorithms and Protocols for Wireless Microsensor Networks." In ICASSP, June 2000 .
[7] A. Sinha and A. P. Chandrakasan. "Operating System and Algorithmic Techniques for Energy Scalable Wireless Sensor Networks." In MDM, pages 199-209. SpringerVerlag, 2001.

[8] C. S. Raghavendra and S. Singh. "PAMAS: Power efficient MAC protocol for multihop radio networks." In ACM Computer Communication Review, 1998.

[9] W. Ye, J. Heidemann, and D. Estrin. "An Energy-Efficient MAC Protocol for Wireless Sensor Networks." In INFOCOM, pages 1567-1576. IEEE, June 2002.

[10] Tijs van Dam and Koen Langendoen. "An Adaptive Energy-Efficient MAC Protocol for Wireless Sensor Networks.” In ACM SenSys, November 2003.

[11] IEEE Computer Society. "IEEE Standard for Part 15.4: Wireless Medium Access Control (MAC) and Physical Layer (PHY) specifications for Low Rate Wireless Personal Area Networks (LR-WPANs).”, October 2003.

[12]Amre El-Hoiydi, Jean-Dominique Decotignie, and Jean Hernandez. « Low Power MAC Protocols for Infrastructure Wireless Sensor Networks." In European Wireless, February 2004. 